We have seen calls for police reform at a higher rate than ever before. The murder of George Floyd highlighted many issues, including the need for the police to carry out their jobs with compassion and the need to humanize the individuals that police interact with on a daily basis. I recently wrote the article, "Universal precautions: A methodology for traumainformed justice," calling for the compassionate treatment of the justice client by police and other justice actors. However, the question remains: how can we expect police officers, correctional officers, and other justice actors to be compassionate if they themselves are not treated with compassion, empathy, and procedural justice within their own organizations?

There have been many police suicides highlighted in the media. The leading cause of police officers' absence from work is psychological injury, and police officers take their own lives at a rate of four suicides to every one police officer murdered. A recent study that has yet to be published by Bucerius, Berardi, Krahn, and Haggerty showed that after going to just two overdose incidents, police officers have higher instances of depression. The key concept here is trauma. Understanding the impacts of trauma is necessary and is needed now more than ever.

This is a call to all police and other justice system leadership to look at the membership through a trauma-informed lens. As the leaders of institutions in justice such as policing and corrections, we need to be mindful of how policy decisions are made. Often, decisions on policy are made from a risk aversion or mitigation standpoint. I had two very personal experiences with policing leadership: one where I felt the leader was compassionate and empathetic and one where I felt the exact opposite. The first event occurred on 12 June 1997, ten days after I started my career with the Edmonton Police Service. On this date, my son was born and died at birth. This was devastating to me and my family. One of the staff sergeants in human resources attended the hospital, showing great care and compassion, informing me to only come back to work when my family and I were ready. This experience early on formed how I wanted to be as a leader within the service. Fast forward a few years and I had two deaths, one was my aunt and the other my grandmother, in very quick succession. As a result, I went to human resources and met with another staff sergeant. I asked if there was any way to extend the bereavement leave due to the emotional impact these two deaths had on me and my family. This person in a leadership role told me, "you get what you get, it's your contract." I felt that there was no compassion or empathy used in this situation, making me feel as if I did not matter to the organization.

Following arbitrary policies is not compassionate leadership. We need to reduce the stigma surrounding mental health and moral injury and listen to the needs of the individual. The concept of "universal precautions for trauma" that I developed for trauma-informed policing when interacting with justice clients can be used with justice actors as well. Justice actors must take a first aid course every two years to learn how to be safe when providing first aid. Statistics show that $0.6 \%$ of the population has Hepatitis C and $0.006 \%$ of the population has HIV. These numbers are small, yet we take special courses. In stark contrast, despite the fact that probably close to $100 \%$ of the police, corrections, and other justice actors have been exposed to some form of trauma, we are not required to take trauma-informed training. However, when not met with compassion, these trauma incidents, such as a death in the family, can manifest themselves as injuries. Such injuries can have an impact on how these individuals interact with the public in general, the justice client, and the people in their personal lives.

For years, I have seen multi-sector justice agencies talk about healthy lifestyles, fitness, exercise, and nutrition. Most police agencies in Canada have an annual physical exam and encourage the membership to see their doctors to ensure they are physically healthy. There is much less emphasis on mental health. We need to see health as a single issue and not separate physical and mental health into two distinct categories. Police leaders must start leading with compassion and empathy. Providing safe spaces for people to talk about their trauma backgrounds and working towards overall health of the membership is a must. This needs to be done for both sworn and civilian staff in the justice system.

The first step in this journey is providing the leadership proper training on trauma and its impacts. There needs to be an understanding at the leadership level of the types of trauma, such as experienced, vicarious, complex, cultural, etc., as well as additional training of people in leadership positions, as to the meaning of being trauma-informed and trauma-aware. Providing training on how to interact with

Correspondence to: Daniel J. Jones, 9620 103A Avenue, Edmonton, AB T5H OH7, Canada. E-mail: Dan.Jones@edmontonpolice.ca

To cite:Jones, D. J. (2021). Compassion as a leadership competency in justice. Journal of Community Safety and Well-Being, 6(4), 160-161. https://doi.org/10.35502/jcswb.231 @ Author(s) 2021. Open Access. This work is distributed under the Creative Commons BY-NC-ND license. For commercial re-use, please contact sales@sgpublishing.ca. gPUBLISHING Published by SG Publishing Inc. CSA Official publication of the Community Safety Knowledge Alliance. 
staff in an empathetic and compassionate way is an opportunity to improve health outcomes for our staff and in turn give them permission to be compassionate and empathetic in the communities they serve.

The next step is instituting compassion as a competency in justice. Often words like accountability, integrity, courage, and community are found in the competency statements and requirements for promotion. Compassion is missing in the mix, and I would argue it is the most important part of the justice system. Canadian systems pride themselves on fairness and inclusivity. Dostoyevsky once wrote, "The degree of civilization in a society can be judged by entering its prisons" (The House of the Dead). I have spent time in several prisons across this country, and I see that compassion is not at the forefront for those incarcerated there. I believe the only way to change that is by bringing compassion to the forefront of all occupations in justice that contribute to the incarceration of people. This would hopefully have a domino effect of compassion, empathy, and trauma-informed policies for everyone.

CONFLICT OF INTEREST DISCLOSURES

The author declares that there are no conflicts of interest.

\section{AUTHOR AFFILIATIONS}

*University of Huddersfield, Huddersfield, UK, and The Edmonton Police Service, Edmonton, AB, Canada. 